\title{
DEPRESSION AS A MEDIATOR BETWEEN BULLYING AND SUICIDAL BEHAVIOR IN CHILDREN AND ADOLESCENTS
}

\author{
Anyerson Stiths Gómez-Tabares \\ Universidad Católica Luis Amigó (Colombia)
}

\begin{abstract}
Few studies have explored the mediating effect of depression on the relationship between school bullying and suicidal behavior. This study analyzed the mediating effect of depression on the association between school bullying and suicide risk and attempt in a sample of 221 children and adolescents between 11 and 17 years old $(M=13.52, S D=1.74)$. Regression analysis showed that depression $(\mathrm{OR}=1.2)$ and school bullying $(\mathrm{OR}=1.4)$ explain between $34 \%$ and $54 \%$ of the variance in suicide risk. Depression $(\mathrm{OR}=1.1)$ and the symptomatology of anxiety, depression, post-traumatic stress, and effects on self-esteem $(\mathrm{OR}=1.3)$ explain between $25 \%$ and $41 \%$ of the variance in suicide attempt. Two structural equation models were constructed to demonstrate that depression mediates the relationship between school bullying, risk, and suicide attempt. These findings will guide intervention strategies to prevent school bullying and suicide risk in school and community settings.

KEY WORDS: victimization, suicide, depression, student.
\end{abstract}

\section{Resumen}

Son escasos los estudios que exploran el efecto mediador de la depresión en la relación entre la intimidación escolar y el comportamiento suicida. Este estudio analizó el efecto mediador de la depresión en la asociación entre la intimidación escolar, el riesgo e intento de suicidio en 221 niños y adolescentes entre los 11 y 17 años $(M=13,52 ; D T=1,74)$. El análisis de regresión mostró que la depresión $(\mathrm{OR}=1,2)$ y la intimidación escolar $(\mathrm{OR}=1,4)$ explican entre el $34 \%$ y el $54 \%$ de la varianza del riesgo suicida. La depresión $(\mathrm{OR}=1,1)$ y la sintomatología de ansiedad, depresión, estrés postraumático y efectos sobre la autoestima $(\mathrm{OR}=1,3)$ explican entre el $25 \%$ y el $41 \%$ de la varianza del intento de suicidio. Se establecieron dos modelos de ecuaciones estructurales que demuestran que la depresión media la relación entre la intimidación escolar, el riesgo e intento de suicidio. Estos hallazgos ayudarán a orientar estrategias de prevención e intervención de la intimidación escolar y el riesgo suicida en contextos escolares y comunitarios.

PALABRAS CLAVE: victimización, suicidio, depresión, estudiante.

Correspondence: Anyerson Stiths Gómez Tabares, Faculty of Psychology and Social Sciences, Psychology Program, Universidad Católica Luis Amigó, Manizales (Colombia). E-mail: anyerspn.gomezta@amigo.edu.co 


\section{Introduction}

Suicidal behavior is a worldwide phenomenon that has taken on epidemic proportions, given the systematic increase, year after year, of cases of completed suicides and failed attempts, especially in the population of children and adolescents, which represents the fifth leading cause of mortality in this population worldwide (Aguirre et al., 2013; Gómez, Núñez, Caballo, Agudelo, \& Grisales, 2019). According to the United Nations (UN, 2017), the world population is approximately 7.6 billion, of which approximately 800,000 people commit suicide each year, which is equivalent to one death every 40 seconds due to this cause (WHO, 2018a, 2018b). According to the World Health Organization (WHO, 2018a), suicide is the second leading cause of death among people aged 15-29 years. Suicide mortality is higher than total mortality caused by war and homicide. Seventy-five percent of the world's suicides occur in low- and middle-income countries (Koyanagi et al., 2019; WHO, 2018a,b). The global picture regarding suicide attempts shows that, there are approximately 20 people who are attempting suicide for every completed suicide (WHO, 2018; PAHO, 2014). In the same vein, WHO (2018a, 2018b) reports more than 20 million suicide attempts per year. In this regard, Cash and Bridge (2009) analyzed the prevalence of suicidal ideation and suicide attempts in young people, finding that the age-adjusted suicide rate among 10- to 19yearolds in the U.S. was 4.16 per 100,000 population, placing suicide as the third leading cause of death in this age group.

According to the Pan American Health Organization (PAHO, 2014), the Americas have a suicide rate of 7.3 per 100,000 inhabitants. Likewise, suicide is the third leading cause of death among children and young people aged 10 to 25 years. In Colombia, according to the National Institute of Legal Medicine and Forensic Sciences (INMLCF, by its acronym in Spanish, 2019), a progressive increase in suicidal behaviors in children and adolescents between 5 and 17 years of age was reported, with a representation of $10.53 \%$ of the total cases of this fatal act during 2018 . Studies conducted in Colombia, and particularly in Caldas (Colombia) corroborate this epidemiological trend by showing that it is in childhood and adolescence where the prevalence of suicide attempts is highest (Álvarez et al., 2013; Amézquita et al., 2008; Cañón et al., 2012; Fuentes et al., 2009; Siabato, Forero, \& Salamanca, 2017; Villalobos, 2009), and, therefore, with a higher risk and vulnerability to completed suicide compared to other stages of the life cycle (Gómez, Núñez, Agudelo, \& Grisales, 2020).

Among the most representative risk factors, it has been found that a history of previous suicide attempts, presence of mood disorders, especially major depression, experiences of bullying, trait impulsivity, low frustration tolerance, history of physical, psychological and sexual abuse, use of psychoactive substances, among others, are strong psychosocial predictors of suicidal behavior in adolescence (Aguirre et al., 2013; Amezquita, González, \& Zuluaga 2008; Bella et al., 2013; Gómez et al., 2019; Gómez et al., 2020; Reed, Nugent, \& Cooper, 2015; Tan, Xia, \& Reece, 2016). Other studies consistently place depressive disorder as one of the main risk factors for suicidal ideation and attempt (Cabrejos, Kruger, \& Salmavides, 2005; Liu et al, 2018; Zakharov, Navratil, \& Pelclova, 2013). In this regard, Mosquera 
(2016), states that disorders with depressive symptoms are the leading cause of death by suicide, and that these in turn present the highest incidence rate in completed suicides.

A chronological review of national and international psychological studies shows that mood disorders, specifically depression, have had higher rates of association with suicidal risk, ideation, and attempt in adolescents and young adults, compared to other psychological and psychiatric disorders (Arenas, Gómez, \& Rondón, 2016; Borowsky, Ireland, \& Resnick, 2001; Fergusson, Woodward, \& Horwood, 2000; Gómez et al, 2019, 2020; Gould et al., 1998; Kessler, Borges, and Walters, 1999; Mortier et al., 2018; Orri et al., 2018; Park and Jang, 2018; Siabato et al. , 2017). In this regard, the study by Nock et al. (2013) found that the disorders with the highest prevalence in suicidal adolescents are major depressive disorder and dysthymia.

Regarding the association between bullying or school bullying and suicidal risk, it has been found that being a victim of school bullying increases the risk of presenting suicide ideation and attempts (Aguirre et al., 2013; Barzilay et al., 2017; Brunstein et al., 2018; Ceballos, Suarez, \& Campo, 2019; Espelage \& Holt, 2013; Fekkes, Pijpers, \& Verloove-Vanhorick, 2004; Valadez, Amezcua, González, Montes, \& Vargas, 2011). It has also been reported that adolescents who face school bullying situations by their peers' present low self-esteem, academic stress, feelings of loneliness and isolation (Valadez et al., 2011). These factors have been widely considered in the literature as risk factors involved in increased suicidal risk in adolescents (Mosquera, 2016).

At the Latin American level, Sandoval, Vilela, Mejía, and Caballero (2018) found that suicidal risk is associated with depression and a high level of school bullying. Similar studies have reported that school bullying or harassment is a risk factor for suicidal behavior and is related to the appearance of depressive symptoms (Fadanellia, Lemos, Soto, \& Hiebra, 2013; Kim, Koh, \& Leventhal, 2005; Kim, Yang, Barthelemy, \& Lofaso, 2018; Klomek et al., 2011). In the Colombian context, the study by Ceballos et al. (2019), with schoolchildren aged 10-17 years, found that school bullying increases the probability of suicidal ideation by $3.1 \%$. A strong statistical association was also found between school bullying, depressive symptoms, and suicidal ideation, with psychosocial factors being more frequent in students aged 14 to 17 years than among those aged 10 to 13 years (Ceballos et al., 2019). This finding is consistent with the study by Aguirre et al. (2013) conducted in the city of Manizales (Colombia), which found that factors such as school bullying are highly associated with an increased risk of suicide ideation and attempt in childhood and adolescence.

Like depression, school bullying has been gaining relevance for psychological research and mental health policies in recent decades, given the adverse psychological consequences it generates. In the case of Colombia, several studies, in Bogotá (Uribe, Orcasita, \& Aguillón, 2012), Cali (Cassiani, Gómez, Cubides, \& Hernández, 2014; Paredes, Álvarez, Lega, \& Vernon, 2008), Santa Marta (Ceballos et al., 2019), Armenia and Manizales (Vega, Fernandez, \& Giraldo, 2017) have reported a prevalence of school bullying in adolescents ranging from $23 \%$ to $67 \%$, and, according to INMLCF (2019) and additional studies (Hinduja \& Patchin, 2010; 
Sampasa-Kanyinga, Roumeliotis, \& Xu, 2014) bullying and bullying victimization are factors associated with the occurrence of mental health problems and an increased risk of suicide ideation and attempts in childhood and adolescence.

This allows us to identify that school bullying is a latent problem in children and adolescents, with multiple edges yet to be explained, precisely because it is a reality that does not disappear, on the contrary, it adapts to new social dynamics. The connection that school bullying has as a predictor of suicidal behavior in children and adolescents has made it a relevant research category (Valadez et al., 2011). Likewise, the relationship between depression, school bullying, and risk and suicide attempt has traditionally been studied under a cause-effect logic, without an analysis of the mediating factors in these relationships. In this sense, there is less production regarding the analysis of the emotional factors that mediate the relationship between school bullying and suicidal behavior in childhood and adolescence (Gómez et al., 2019). In particular, the role of depression as a mediating variable between school bullying, risk and suicide attempt in children and adolescents located in a context of psychosocial risk.

In accordance with the above, and the complexity of this phenomenon, the objectives of this study are 1, to identify the prevalence of suicide risk and attempt, as well as the presence of depressive symptomatology and risk of school bullying. 2, to analyze the relationship between school bullying, depression and risk and previous suicide attempt, and, 3, to analyze the mediating effect of depression between the association of school bullying and risk and previous suicide attempt in children and adolescents who are at psychosocial risk (Manizales, Colombia). For Gómez et al. (2019) this type of study is a valuable input for the design and validation of psychosocial and psychoeducational strategies aimed at the detection, prevention and intervention of suicidal behavior, under a contextual perspective and with empirical support.

\section{Method}

\section{Participants}

A non-probabilistic purposive sample was used, which consisted of 221 school children and adolescents at psychosocial risk, between 11 and 17 years of age $(M=$ 13.52, $S D=1.739)$, who are in sixth to eleventh grades in an educational institution in Manizales (Colombia).

The sample was selected taking into account that the highest rate of attempted and completed suicides in Manizales and Colombia is reported in children and adolescents according to the social observatory of the Caldas Sectional Territorial Management (by its name in Spanish, Dirección Territorial Seccional Caldas) (Delgado et al., 2017) and the INMLCF (2019). Another inclusion criterion was that the students were part of a context of high psychosocial risk. The gender distribution was 102 males (46.2\%) and 119 females (53.8\%).

It is worth mentioning that the educational institution in which the study was carried out is located in the Ciudadela del Norte commune in the city of Manizales (Colombia), which has a context of high psychosocial vulnerability, and high levels 
of insecurity, social violence and poverty. Likewise, the children, adolescents and their families are residents of the same commune, of which $100 \%$ are of socioeconomic stratum $1(n=36,20.8 \%)$ and $2(n=159,71.9 \%)$.

Regarding family typology, $53.8 \%(n=119)$ were nuclear families, $19.5 \%(n=$ 43) were extended families; $18.9 \%(n=42)$ were single-parent families with maternal predominance and $4.5 \%(n=10)$ were mixed or reconstituted families; there were 7 cases (3.2\%) with missing values in terms of family constitution.

\section{Instruments}

a) Socio-demographic self-report ad hoc. A socio-demographic self-report form prepared by the researcher and approved by experts was applied, with information on age, sex, socioeconomic stratum, family type, school grade, and history of suicide attempts and number of attempts. The sociodemographic variables in the form were coded numerically, assigning a numerical value to each response and a label to that value. The suicide attempt variable was calculated from the report of children and adolescents of at least one suicide attempt in the last year, with a dichotomous response option of Yes or No. A numerical value of 0 was assigned to cases with no history of suicide attempt (No) and 1 to cases that reported at least one suicide attempt in the last year (Yes).

b) Plutchik Suicide Risk Scale (Plutchik \& Van Praag, 1989). It is a Likert-type scale composed of 15 items, with a dichotomous response option of Yes or No. Each affirmative response scores 1 , for a total of 15 points. Scores above 6 indicate suicidal risk (Rubio et al., 1998; Santana \& Santoyo, 2018). The scale assesses previous self-harm attempts (Have you ever tried to take your own life?), intensity of current suicidal ideation (Have you ever told anyone that you wanted to commit suicide?), feelings of depression (Are you depressed now?), hopelessness (Do you see your future as hopeless?) and others, to estimate suicide risk. The Spanish version validated by Rubio et al. (1998) was used, which reported an internal consistency of .90, as well as a sensitivity and specificity of $88 \%$ for a cut-off point of 6 for suicidal risk. The scale has been widely used in the Colombian population showing a reliability ranging from .73 to .89 (Aguirre et al, 2013; Cañón et al., 2012; Castaño et al, 2015; Gómez et al., 2019, 2020; Sandoval et al., 2018). For this study, an internal consistency analysis was performed with Cronbach's alpha, showing a coefficient of .83.

c) CIE-A and CIE-B School Bullying Questionnaire (Cuevas, Hoyos, \& Ortiz, 2009). It is a Likert-type scale composed of 36 items for the detection of school bullying, which includes three subscales: 1 . situation of victimization by bullying (physical, verbal, social and coercion) ("They threaten me to make me do things I do not want"), 2. Intimidation by respondents ("I break their things on purpose"), and, 3. Symptomatology of anxiety, depression, post-traumatic stress and effects on self-esteem ("Sometimes I hate myself") (Moratto et al., 2012). The first two subscales have as response option never, seldom and almost always, which are scored from 0 to 2, and, the third subscale has dichotomous response option of Yes or No. The age range for the application is 8 to 18 years. The version 
validated for Colombia by Moratto, Cárdenas and Berbesí (2012) was implemented, in which the multidimensionality of the questionnaire was confirmed under the structure of the three dimensions mentioned. The questionnaire presents the following risk classification criteria for the total scale; no risk (0 points), low risk (8 to 14 points), medium risk (15 to 29 points) and high risk (>30 points). For the subscales of bullying victimization and respondent bullying, the risk rating criteria are: no risk ( 0 points), low risk (1 to 5 points), medium risk ( 6 to 11 points) and high risk (>12 points). For the symptomatology scale: no risk (0 points), low risk (1 to 3 points), medium risk (4 to 6 points), and high risk ( $>6$ points) (Moratto et al., 2012). The questionnaire has reported internal consistency indices with Cronbrach's alpha between .83 and .89 and factor analysis confirms the dimensionality of the scale in the three factors indicated (Ceballos et al., 2019; Cuevas et al., 2009, Moratto et al., 2012). The internal consistency analysis with Cronbach's alpha for this study evidenced a coefficient of .79 for bullying victimization, .65 for bullying and .79 for symptomatology. For the total school bullying scale Cronbach's alpha was .84.

d) Children's Depression Inventory (CDI; Kovacs, 1992). It is a Likert-type scale composed of 27 items, which contains two scales (dysphoria and negative selfesteem), where three situations are posed and the statement that best describes it is selected as an answer option. It evaluates the presence or not of depression, ("I am always sad"). The age range for application is 7 to 17 years, with a Cronbach's Alpha of .78 for a cut-off point of 19 (Abello et al., 2014). This questionnaire has been used in Colombia with schoolchildren and adolescents in the cities of Barranquilla (Abello et al., 2014) and Neiva (Herrera et al, 2009) reporting good internal consistency indices, ranging between .74 and .83. For this study, an internal consistency analysis was performed with Cronbach's alpha, showing a coefficient of .84 .

\section{Procedure}

The information for this research was collected at the end of the second semester of 2019. The application of the instruments was carried out collectively in the classrooms. The application lasted between 45 and 50 minutes per group. In accordance with law 1090 of 2006 and resolution 008430 of 1993, this research obeyed the ethical principles of respect, privacy and dignity, ensuring the confidentiality and anonymity of the participants, as established in article 26 and 50. It is important to point out that we had the approval of the educational institution, the informed consent of the parents and the assent of the participants. Likewise, the results obtained were returned to the institutional level. The ethics committee of the Universidad Católica Luis Amigó, Manizales (Colombia), approved the research project and the protocol of scales applied.

\section{Data analysis}

The SPSS V. 25 statistical package was used for the statistical analysis. A descriptive univariate analysis of the prevalence of suicide risk and attempt, risk of 
school bullying and depression was initially performed with estimation of frequencies, percentages, means and standard deviation, according to the nature of the variables. Once this was done, a comparative analysis of suicidal risk as a function of the psychological and sociodemographic variables was performed. For this, the nonparametric Mann-Whitney $\mathrm{U}$ and Kruskal-Wallis $\mathrm{H}$ tests were used, due to the fact that in the application of the Kolmogorov - Smirnov test it was found that the variables were not normally distributed $(p>.05)$. R Studio Cloud was used to calculate the effect size of the differences found in the comparative analysis, which was estimated using the eta squared statistic $\left(\eta^{2}\right)$. The procedure and interpretation established by Fritz, Morris and Richler (2012) was followed: small effect (.01), medium effect (.06), large effect (.14). Subsequently, a correlation analysis was performed using Spearman's Rho coefficient, and a binary logistic regression analysis was performed to identify the variables with the highest predictive value on suicide risk and attempt.

Finally, two structural equation models are proposed to determine the direct and indirect effect between the variables considered in this study. Amos v. 24.0 software was used for structural equation modeling. Total, direct and indirect effects were calculated using the bootstrap method with a 95\% confidence interval (Byrne, 2016; Hayes, 2018). To assess the goodness-of-fit of the models, we used chi-square values $\left(\chi^{2}\right)$, probability level $(p \geq .05)$, comparative fit index (IFI $\geq .90$ and $\left.C F \mid \geq .90\right)$, goodness-of-fit index (GFI $\geq .90$ ) and its corresponding corrected (AGFI $\geq .90$ ), normalized fit index (NFI $\geq .90$ ) and Tucker - Lewis index (TLI $\geq .90)$ and root mean square residual of approximation (RMSA $\leq$.08) (Byrne, 2016; McArdle \& Nesselroade, 2014).

\section{Results}

Table 1 shows the descriptive analysis of the prevalence of behaviors associated with suicide, school bullying and depressive symptomatology. At the general level, it was found that $24.9 \%$ of children and adolescents reported suicidal thoughts in the last 6 months and $16.7 \%$ had attempted suicide.

Of the 37 people who had attempted suicide, $15.4 \%(n=34)$ had attempted it once, 3.6\% $(n=8)$ twice, 1.8\% $(n=4)$ three times, and $4.1 \%(n=9)$ had attempted it four times. The suicide risk factor identified from the Plutchik scale shows that, of the 221 students, $20.4 \%$ obtained scores indicating suicide risk. Likewise, 16.7\% reported symptomatic indicators for depression.

Regarding school bullying, it was found that $82.4 \%$ of the population reported some level of risk of being a victim of bullying, whether physical, verbal, social or coercion, with a specificity of $3.2 \%$ of high risk. In smaller proportion, $46.6 \%$ reported risk for bullying by those who respond to bullying situations, however, the risk is low level. Regarding the prevalence of symptoms of anxiety, depression, posttraumatic stress disorder and effects on self-esteem as a result of school bullying situations, a risk was found in $90.5 \%$ of the population, with a specificity of $25.3 \%$ for high risk. 
Table 1

Descriptive analysis of suicide risk and attempt, school bullying and depressive symptomatology

\begin{tabular}{|c|c|c|c|}
\hline Variables & Levels & $n$ & $\%$ \\
\hline \multirow{2}{*}{ Suicide risk } & Risk & 45 & 20.4 \\
\hline & No risk & 176 & 79.6 \\
\hline \multirow{2}{*}{ Previous suicide attempt } & No & 184 & 83.3 \\
\hline & Yes & 37 & 16.7 \\
\hline \multirow{2}{*}{ Symptoms of depression } & No & 37 & 16.7 \\
\hline & Yes & 184 & 83.3 \\
\hline \multirow{4}{*}{ Bullying victimization } & No risk & 39 & 17.6 \\
\hline & Low risk & 126 & 57.0 \\
\hline & Medium risk & 49 & 22.2 \\
\hline & High risk & 7 & 3.2 \\
\hline \multirow{4}{*}{ Intimidation by respondents } & No risk & 118 & 53.4 \\
\hline & Low risk & 96 & 43.4 \\
\hline & Medium risk & 7 & 3.2 \\
\hline & High risk & 0 & 0 \\
\hline \multirow{4}{*}{$\begin{array}{l}\text { Symptomatology of anxiety, } \\
\text { depression, post-traumatic } \\
\text { stress disorder and effects on } \\
\text { self-esteem }\end{array}$} & No risk & 21 & 9.5 \\
\hline & Low risk & 84 & 38 \\
\hline & Medium risk & 60 & 27.1 \\
\hline & High risk & 56 & 25.3 \\
\hline
\end{tabular}

A comparative analysis of the psychological variables was carried out according to sex and age ranges, using the Mann-Whitney $U$ test. It was found that females presented significantly $(p<.001)$ higher scores in suicide attempt $(z=-2.55, p=.011$, $\left.\eta^{2}=.029\right)$, depression $\left(z=-2.344, p=.019, \eta^{2}=.025\right)$ and symptomatology of anxiety, depression, post-traumatic stress disorder and effects on self-esteem ( $z=$ 2.891, $p=.004, \eta^{2}=.038$ ). In relation to age, students aged 14 to 17 years, compared to those aged 11 to 13 years, presented significantly higher scores on the variables of depression $\left(z=-2.346, p=.019, \eta^{2}=.025\right)$ and suicidal risk $(z=-2.126$, $p=.033, \eta^{2}=.02$ ). When evaluating the effect size of significant differences in terms of sex and age ranges, using the eta squared statistic $\left(\eta^{2}\right)$, a very small effect size was identified $\left(\eta^{2}<\right.$.039) (Fritz et al., 2012).

Table 2 presents the comparative analysis between the groups with suicidal risk and those without risk in relation to the different study variables. Since nonparametric statistics were used, in addition to the mean value and standard deviation, the mean and median ranges were reported, as well as the $z$ values of the Mann-Whitney $\mathrm{U}$ comparison test and the $p$ value of significance. 


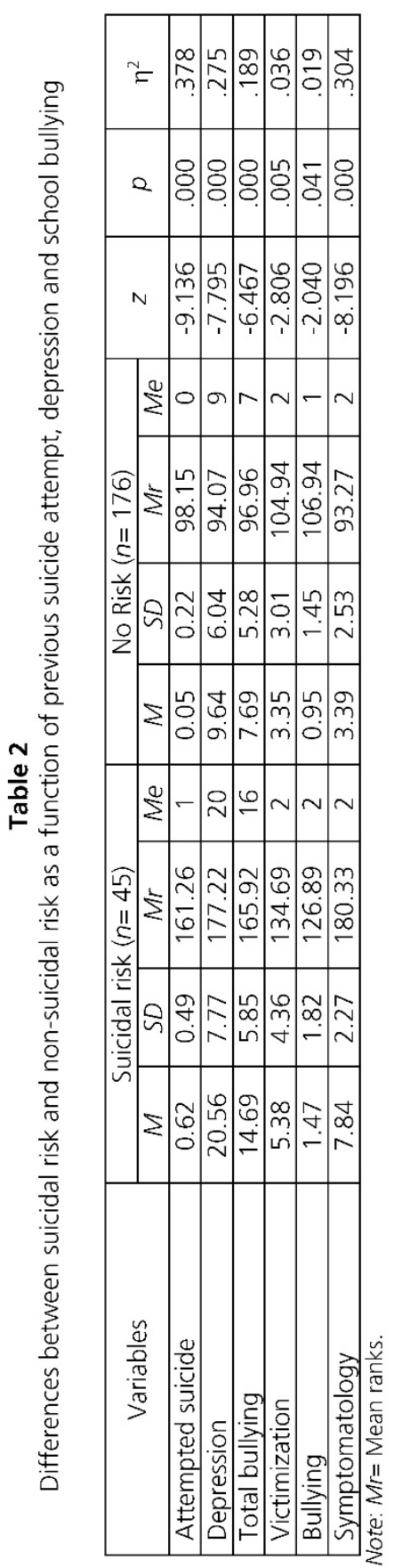


It was identified that schoolchildren at risk of suicide presented significantly ( $p<$ .001) higher scores in history of suicide attempt, depression, total school bullying, bullying victimization and anxiety symptomatology, depression, post-traumatic stress disorder and effects on self-esteem. The calculation of effect size using index $\eta^{2}$ evidences that the statistical differences found were independent of effect size, presenting values above 0.039 (Fritz et al., 2012). As for bullying by respondents, despite presenting a statistically significant difference $(p<.05)$, the effect size was low $\left(\eta^{2}=.019\right)$.

Table 3 shows the results of the correlational analysis of the various study variables using Spearman's Rho coefficient. Statistically significant correlations, of positive sign, were found between suicidal risk and the variables of previous suicide attempt, depression, total school bullying, bullying victimization, bullying by respondents, and symptomatology of anxiety, depression, post-traumatic stress disorder and effects on self-esteem. These findings show that depression and school bullying are strongly associated with suicide risk and attempt.

Table 3

Spearman correlation coefficient between suicide risk and attempt, depression and school bullying

\begin{tabular}{|c|c|c|c|c|c|c|c|}
\hline Correlations & 1 & 2 & 3 & 4 & 5 & 6 & 7 \\
\hline 1. Suicidal risk & & $.557^{* *}$ & $.645^{* *}$ & $.568^{* *}$ & $.332^{\star *}$ & $.165^{*}$ & $.639^{* *}$ \\
\hline 2.Attempted suicide & & _ & $.415^{* *}$ & $327^{* *}$ & $.149^{*}$ & -.009 & $.436^{* *}$ \\
\hline 3.Depression & & & _ & $605^{* *}$ & $.405^{* *}$ & $.168^{*}$ & $.635^{\star *}$ \\
\hline 4.Total school bullying & & & & - & $846^{* *}$ & $.464^{* *}$ & $.810^{\star \star}$ \\
\hline 5.Victimization & & & & & 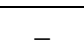 & $.350^{* *}$ & $.456^{\star *}$ \\
\hline 6.Bullying & & & & & & & .122 \\
\hline 7.Symptomatology & & & & & & & \\
\hline
\end{tabular}

Note: ${ }^{*} p \leq .01$ (bilateral), ${ }^{*} p \leq .05$ (bilateral).

On the other hand, Table 4 shows two binary logistic regression models using the forward method: Wald, in order to identify the role of depression and school bullying variables in the variance of suicide risk and attempt. The first model used the suicide risk factor and, in the second, the history of suicide attempt as dependent variables. The variables of depression and school bullying were the independent variables. Both the first model (chi Hosmer and Lemeshow $=3.176, d f=8, p=.923$ ) and the second (chi Hosmer and Lemeshow $=2.511, d f=8, p=.961$ ) presented very good indicators of goodness of fit.

The first model showed that the independent variables explained between $34 \%\left(R^{2}\right.$ Cox and Snell= .341) and 54\% $\left(R^{2}\right.$ Nagelkerke $\left.=.537\right)$ of the suicide risk factor, and the second model explained between $25 \%\left(R^{2}\right.$ Cox and Snell $\left.=.247\right)$ and $41 \%\left(R^{2}\right.$ Nagelkerke $\left.=.41\right)$ of the variation in suicide attempt.

In these models the odds ratios (OR) show how much the probability of belonging to the suicide risk and attempt categories increases according to the variance of the independent variables. In model 1, depression increased the suicide risk factor by $1.2 \%(\mathrm{OR}=1.153,95 \% \mathrm{Cl}=1.074-1.239)$ and overall school bullying 
by $1.4 \%(\mathrm{OR}=1.422,95 \% \mathrm{Cl}=1.210-1.672)$. For model 2 , depression increased by $1.1 \%(\mathrm{OR}=1.128, \mathrm{Cl} 95 \%=1.054-1.207)$ and symptomatology of anxiety, depression, post-traumatic stress disorder and effects on selfesteem increased by $1.3 \%(O R=1.309, C I 95 \%=1.091-1.571)$ the probability of suicide attempt.

Table 4

Binary logistic regression analysis

\begin{tabular}{|c|c|c|c|c|c|c|c|c|}
\hline \multirow{2}{*}{ Variables } & \multirow{2}{*}{$\beta$} & \multirow{2}{*}{ SE } & \multirow{2}{*}{$\chi^{2}$ Wald } & \multirow{2}{*}{$d f$} & \multirow[b]{2}{*}{$p$} & \multirow{2}{*}{ OR } & \multicolumn{2}{|c|}{$95 \% \mathrm{Cl}$} \\
\hline & & & & & & & Lower & Upper \\
\hline \multicolumn{9}{|c|}{ Model 1. Suicide risk factor as dependent variable } \\
\hline $\begin{array}{l}\text { Total school } \\
\text { bullying }\end{array}$ & .352 & .083 & 18.182 & 1 & .000 & 1.422 & 1.210 & 1.672 \\
\hline Depression & .143 & .036 & 15.320 & 1 & .000 & 1.153 & 1.074 & 1.239 \\
\hline \multicolumn{9}{|c|}{ Model 2. History of suicide attempt as dependent variable } \\
\hline Depression & .120 & .035 & 12.030 & 1 & .001 & 1.128 & 1.054 & 1.207 \\
\hline Symptomatology & 269 & .093 & 8.389 & 1 & .004 & 1.309 & 1.091 & 1.571 \\
\hline
\end{tabular}

To establish the direct and indirect effects that the variables of depression and school bullying have on suicide risk and attempt, two structural equation models were estimated through the weighted least squares method, since it allows working with variables that do not meet the univariate normality assumption and provides consistent and unbiased estimates with relatively small sample sizes (Byrne, 2016). Table 5 shows the goodness-of-fit indicators of the two proposed models, whose results show that they present an adequate fit to the data (McArdle \& Nesselroade, 2014).

Table 5

Goodness-of-fit statistics of structural models for predicting suicide risk and attempt

\begin{tabular}{|c|c|c|c|c|c|c|c|c|c|c|}
\hline Model & $\chi^{2}$ & $g l$ & $p$ & IFI & CFI & NFI & TLI & GFI & AGFI & RMSEA \\
\hline 1 & 0.329 & 1 & .566 & 1.005 & 1.0 & .998 & 1.051 & .999 & .991 & .000 \\
\hline 2 & 2.301 & 1 & .129 & .987 & .986 & .977 & .917 & .995 & .948 & .070 \\
\hline
\end{tabular}

In model 1 (Figure 1), the variables of depression and anxiety symptomatology, depression, post-traumatic stress disorder and effects on self-esteem were taken as mediators between school bullying, suicide risk and suicide attempt. School bullying was found to explain $36 \%\left(R^{2}=.362,95 \% \mathrm{Cl}=0.271-0.465 ; p=.001\right)$ of the variance in depression and $69 \%\left(R^{2}=.688,95 \% \mathrm{Cl}=0.619-0.760, p=.001\right)$ of the symptomatology variable. It was also found that the variables of school bullying, depression and previous suicide attempt explained $65 \%$ of the risk of suicide $\left(R^{2}=\right.$ $.65,95 \% \mathrm{Cl}=0.554-0.741, p=.001)$. Likewise, previous suicide attempt is explained by $29 \%\left(R^{2}=.289,95 \% \mathrm{Cl}=0.176-0.420, p=.001\right)$ by the direct effect of depression and symptomatology variables. 
Figure 1

Structural equation model 1: depression and symptomatology as mediators between school bullying, suicide risk and suicide attempt

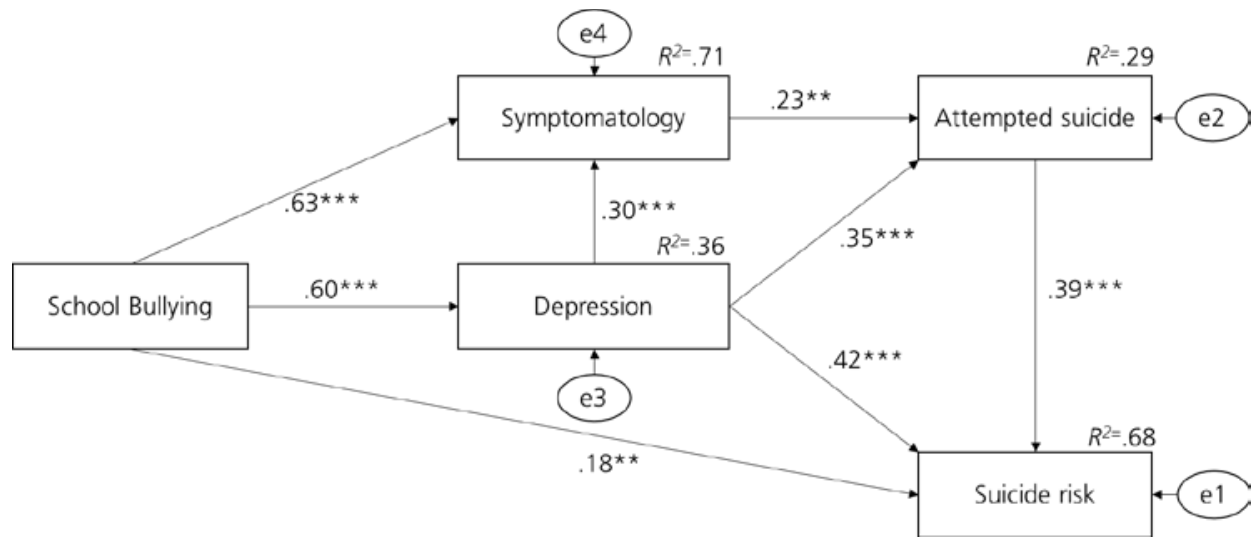

Note: ${ }^{*} p<.05 ;{ }^{* *} p<.1 ;{ }^{* *} p<.001$.

Table 6 shows the total, direct and indirect standardized effects of the study variables (model 1). The largest total effect on suicide risk was provided by school bullying (0.576), followed by depression (0.569). Likewise, school bullying contributed the highest indirect effect on suicide risk. As for previous suicide attempt in the last year, depression had the highest total (0.424) and direct (0.358) effect, followed by the indirect effect of school bullying (0.397). All total, direct and indirect effects were statistically significant $(p<.01)$.

In model 2, only depression was used as a mediating variable between school bullying, suicide risk and suicide attempt (see Figure 2). The reason for this is to present a much more parsimonious empirical model. Given that the symptomatology variable presented the smallest, although significant, total, direct, indirect effects on suicide risk and attempt compared to the other variables, the decision was made to present an additional model without the symptomatology variable.

It was found, similar to model 1 , that school bullying explained $37 \%\left(R^{2}=.367\right.$, $95 \% \mathrm{Cl}=0.274-0.472, p=.001)$ of the variance in depression, and, the school bullying variables, in conjunction with the mediation of depression and previous suicide attempt, explained $65 \%$ of the risk of suicide $\left(R^{2}=.65,95 \% \mathrm{Cl}=0.547\right.$ $0.740, p=.001)$. Previous suicide attempt was explained by $26 \%\left(R^{2}=.263,95 \%\right.$ $\mathrm{Cl}=0.145-0.394, p=.001)$ by the direct effect of depression and indirect effect of school bullying (see Figure 2).

Table 7 shows the total, direct and indirect standardized effects of the study variables (model 2). All total, direct and indirect effects were statistically significant $(p<.01)$. 


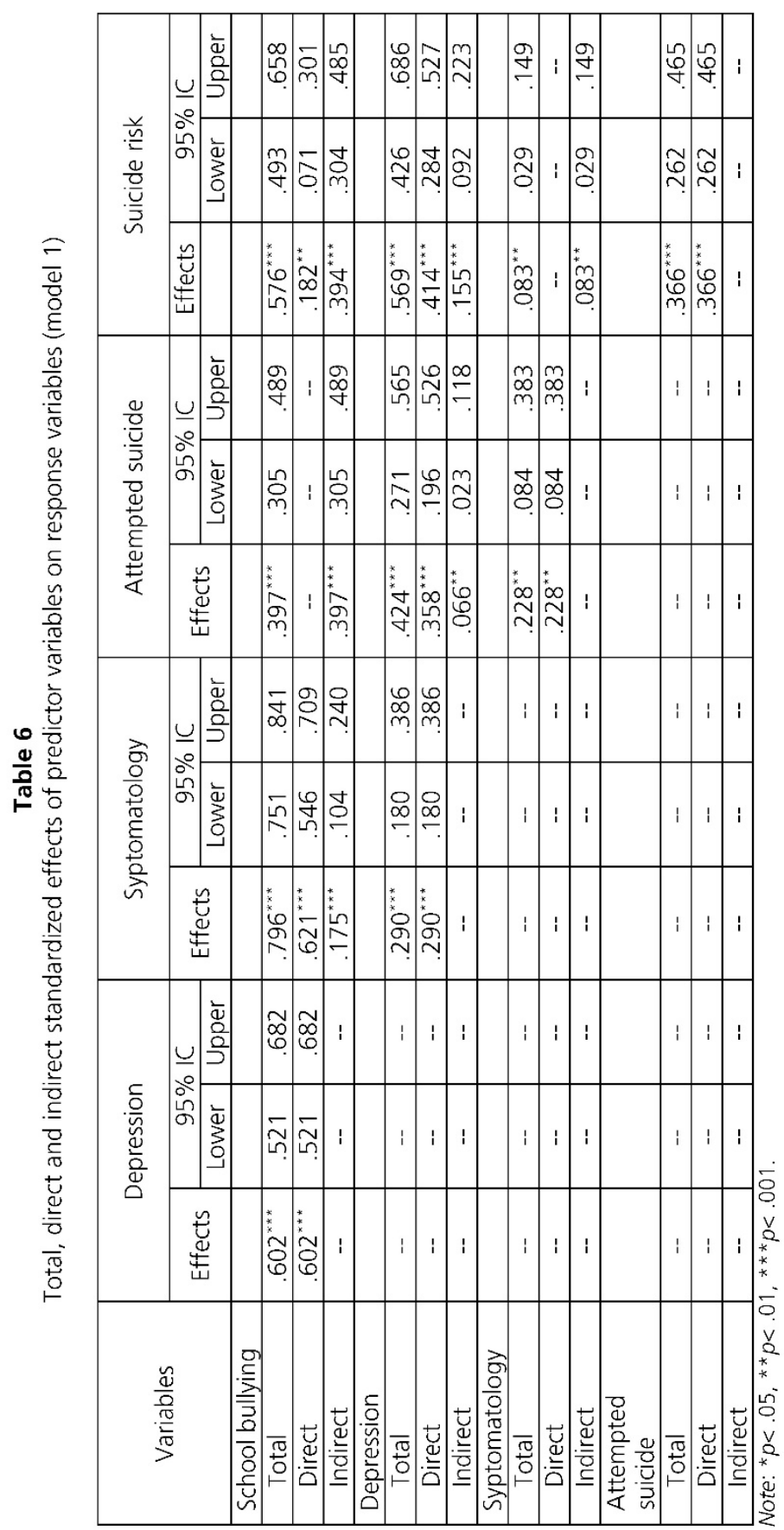


Figure 2

Structural equation model 2: depression mean the relationship between school bullying, suicide risk and suicide attempt

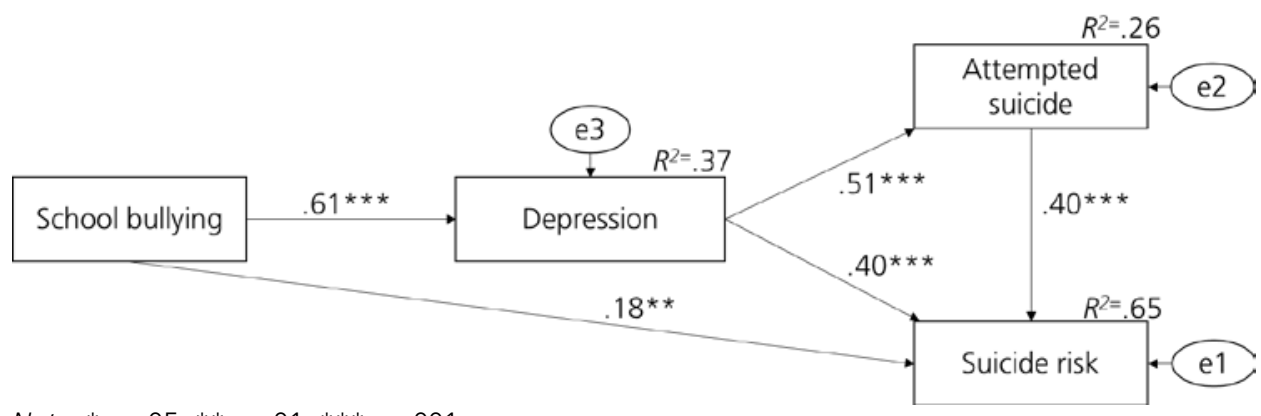

Note: ${ }^{\star} p<.05,{ }^{* *} p<.01,{ }^{* *} p<.001$.

Table 7

Total, direct and indirect standardized effects of predictor variables on response variables (model 2)

\begin{tabular}{|c|c|c|c|c|c|c|c|c|c|}
\hline \multirow{3}{*}{ Variables } & \multicolumn{3}{|c|}{ Depression } & \multicolumn{3}{|c|}{ Attempted suicide } & \multicolumn{3}{|c|}{ Suicide risk } \\
\hline & \multirow{2}{*}{ Effects } & \multicolumn{2}{|c|}{$95 \%$ IC } & \multirow{2}{*}{ Effects } & \multicolumn{2}{|c|}{$95 \%$ IC } & \multirow{2}{*}{ Effects } & \multicolumn{2}{|c|}{$95 \% \mathrm{IC}$} \\
\hline & & Lower & Upper & & Lower & Upper & & Lower & Upper \\
\hline \multicolumn{10}{|l|}{ School bullying } \\
\hline Total & $.605^{* * *}$ & .523 & .687 & $.311^{* * *}$ & .217 & .405 & $.545^{* * *}$ & .452 & .635 \\
\hline Direct & $.605^{* * *}$ & .523 & .687 & ---- & ---- & ---- & $.178^{* *}$ & .065 & .297 \\
\hline Indirect & ---- & $\begin{array}{l}--- \\
\end{array}$ & ---- & $.311^{* * *}$ & .217 & .405 & $.367^{* * *}$ & .272 & .461 \\
\hline \multicolumn{10}{|l|}{ Depression } \\
\hline Total & $\begin{array}{ll}--- \\
\end{array}$ & $\begin{array}{ll}--- \\
\end{array}$ & $\begin{array}{ll}--- \\
\end{array}$ & $.513^{* * *}$ & .381 & .628 & $.606^{* * *}$ & .473 & .723 \\
\hline Direct & $-\cdots$ & -+- & $-\cdots$ & $.513^{* * *}$ & .381 & .628 & $.403^{* * *}$ & .273 & .515 \\
\hline Indirect & ---- & $-\cdots$ & $-\cdots$ & ---- & +--- & $\begin{array}{ll}--- \\
\end{array}$ & $.203^{* * *}$ & .135 & .275 \\
\hline \multicolumn{10}{|c|}{ Attempted suicide } \\
\hline Total & ---- & ---- & ---- & ---- & ---- & ---- & $.397^{* * *}$ & .288 & .500 \\
\hline Direct & $-\cdots$ & $-\cdots$ & $-\cdots$ & $-\cdots$ & $-\cdots-$ & $-\cdots$ & $.397^{* * *}$ & .288 & .500 \\
\hline Indirect & $\begin{array}{ll}--- \\
\end{array}$ & ---- & ---- & ---- & ---- & ---- & ---- & --- & ---- \\
\hline
\end{tabular}

Note: ${ }^{\star} p<.05,{ }^{*} p<.01,{ }^{* * *} p<.001$.

\section{Discussion}

The present study had the following objectives: 1 , to identify the prevalence of suicide risk and attempt, depression symptomatology and risk of school bullying. 2, to analyze the relationship between school bullying, depression and risk and previous suicide attempt, and, 3, to analyze the mediating effect of depression between the association of school bullying and risk and previous suicide attempt in a sample of children and adolescents at psychosocial risk (Manizales, Colombia).

Regarding the first objective, we found a prevalence of suicide attempt of $16.7 \%$ and a risk factor of $20.4 \%$ in the population studied. This finding is consistent with what has been found in other studies (Andrade \& Gonzáles, 2017; Ceballos et al., 2015; Fuentes et al., 2009; Gómez et al., 2019, 2020; Siabato et al., 2017; Villalobos, 2009), indicating that, on average, a quarter of the school population presents suicide risk indicators, including a history of suicide attempts, 
self-injurious behaviors, death-oriented thoughts and fantasies, and indicators associated with depression and hopelessness. It is also important to highlight that $16.7 \%$ of the students presented symptomatic indicators of depression.

The high percentage of school bullying risk, independent of level, reported in this study, is consistent with the work of Koyanagi et al. (2019), with a sample of 134,229 school adolescents aged 12 to 15 years, from 43 countries in the world, by evidencing that $30.4 \%$ of the total population had experienced situations of physical and psychological bullying in the last 30 days, showing, in addition, an association with significantly higher odds of attempted suicide in adolescents in all countries ( $\mathrm{OR}=3.06$ pooled, $95 \% \mathrm{Cl}=2.73-3.43)$. In this regard, the meta-analysis conducted by Modecki, Minchin, Harbaugh, Guerra and Runions (2014), based on 80 studies with adolescents, showed an overall school bullying prevalence of $36 \%$, and concluded that the involvement of children and adolescents in polyaggression should be considered a main target for psychosocial intervention.

In relation to the second objective, it was found that children and adolescents with suicidal risk presented significantly higher scores in total school bullying, bullying victimization, anxiety symptomatology, depression, post-traumatic stress disorder and effects on self-esteem. Correlation analysis showed significant associations between total school bullying, depression, suicide risk and suicide attempt. Likewise, the binary logistic model showed that total school bullying $(\mathrm{OR}=$ 1.4) and depression $(O R=1.2)$ increase the probability of suicidal risk, and presenting symptomatology (anxiety, depression, posttraumatic stress and effects on selfesteem) increases the probability of suicide attempt by 1.3 times (OR=1.3).

These findings are consistent with several studies that have highlighted the role of depression in predicting suicidal risk, ideation, and attempt in childhood and adolescence (Borges, Benjet, Medina-Mora, Orozco, \& Nock, 2018; Castaño et al., 2015; Croarkin et al., 2018; Fergusson et al., 2000; Franklin et al., 2017; Kessler et al., 1999; Kodish et al., 2016; Orri et al., 2018). In this regard, Cash and Bridge (2009) found that $60 \%$ of adolescent suicide victims presented a mood disorder, and, at least $85 \%$ of clinically depressed adolescents presented suicidal ideation. Additional studies consistently evidence that depression is one of the most important predictors of suicidal behavior in childhood and adolescence (Amezquita et al., 2008; Arenas et al., 2016; Gomez et al., 2020; Mortier et al., 2018; Park \& Jang, 2018; Reed et al., 2015; Siabato et al., 2017; Villalobos, 2009).

The association between depression and school bullying in predicting suicidal risk in children and adolescents found in this study is consistent with other similar research that has reported that traditional school bullying and cyberbullying have been associated with depression, suicidal ideation and attempts in schoolchildren (Hinduja \& Patchin, 2010, 2018; Geoffroy et al., 2016; Kowalski \& Limber, 2013; Sandoval et al., 2018; Schneider, O'Donnell, Stueve, \& Coulter, 2012), In this regard, the meta-analysis conducted by Van Geel, Vedder and Tanilon (2014) confirms the strength of this association.

In this regard, the study by Kodish et al. (2016), with a population of 5,429 adolescents, found that all types of school bullying were associated with depression and suicidal risk, a finding convergent with additional studies that evidenced an association between school bullying, depression, and suicidal risk in school 
adolescents (Brunstein et al., 2018; Ceballos et al., 2019; Kim et al., 2018; Sandoval et al., 2018). The longitudinal study by Geoffroy et al. (2016) found that 13-yearold adolescents who were victims of school bullying presented higher odds of presenting suicidal ideation $(O R=2.27)$ and suicide attempt $(O R=3.05)$ two years later, compared to those who were not bullied. Likewise, 13- and 15-year-old adolescent victims of school bullying had a higher risk of suicidal ideation (OR= 5.41). Brunstein et al. (2018) also found this longitudinal association between school bullying-physical, verbal, and relational-, depression, ideation, and suicide attempt in the study with a sample of 1,933 adolescents from ten European countries.

Although these findings support inferences based on the existing academic literature, the relationship between depression, suicidal behavior and school bullying is still under investigation, with a special interest in the mediating role of depression and other emotional factors in the association between school bullying and suicidal behavior in children and adolescents. Few studies currently explore the mediating effect of depression in the relationship between school bullying and suicidal behavior, particularly in children and adolescents at psychosocial risk.

For Koyanagi et al. (2019), Van Geel et al. (2014) the association between school bullying and suicide may be mediated by various psychological factors, including low selfesteem, depression, hopelessness, adverse family events and history of childhood maltreatment. In this case, and in coherence with the third objective, the two structural equation models presented show the importance of the mediating role of emotional factors, including symptoms of anxiety, depression, post-traumatic stress disorder and effects on selfesteem in understanding the relationship between school bullying and suicide risk and attempt in children and adolescents at psychosocial risk who were part of this study. In particular, depression mediates the relationship between school bullying, suicide risk and suicide attempt, while providing the most significant total effect on suicide attempt.

Previous studies have provided evidence that depression at least partially mediates the relationship between traditional and cyber school bullying and suicide attempt in schoolchildren (Bauman, Toomey, \& Walker, 2013; Kim et al., 2018; Sampasa-Kanyinga et al., 2014). The study by Kim et al. (2018) with a sample of 11,341 U.S. schoolchildren is one of the most current studies providing strong evidence regarding the mediating role of depression among four types of peer victimization: school bullying, cyberbullying, physical and sexual dating violence, and suicide attempts.

The results of this study provide additional evidence on the impact of school bullying on the mental health of children and adolescents, which opens multiple avenues to be explored regarding the understanding of more complex relationship patterns, where emotional factors better mediate the impact of different types of peer violence and victimization on the prediction of suicidal risk, both for ideation, attempted and completed suicide in childhood and adolescence.

The reported findings have important implications for the development and consolidation of strategies for early detection, prevention and psychosocial intervention of suicidal behavior in school and community contexts (Ceballos et al., 2019; Gómez et al., 2019; Wahlbeck, 2015). The importance of evaluation and continuous improvement in the field of psychosocial and psychoeducational 
intervention to detect cases of bullying and school victimization is highlighted, an aspect that will allow the deployment of prevention and intervention actions on the emotional and mood effects that can lead to an increased risk of suicidal behavior in children and adolescents. In addition, it is considered crucial that educational institutions and psychosocial professionals who accompany school training processes have clear protocols for evaluation, detection and inter-institutional approach to mitigate school bullying and the negative consequences on the mental health of schoolchildren.

Finally, the findings of this study should be interpreted in the light of several limitations. First, being a cross-sectional study, it was not possible to determine the impact over time of school bullying experiences on the mental health of children and adolescents. For future studies, the use of longitudinal methodologies is recommended in order to corroborate these findings and provide additional evidence on the impact over time of school bullying events on depression and suicidal behavior in children and adolescents.

Second, given that this was a population in a context of psychosocial risk and socioeconomic vulnerability, there are many other external factors not contemplated in this study that may be associated with suicide risk and attempt.

To remedy this limitation, it is recommended that future studies use methodologies of explanatory scope and contemplate the analysis of social, family and contextual factors (Sánchez, 2013, 2017), and comparisons with other diverse sociocultural and socioeconomic contexts. This raises two lines of study for future research. The first is aimed at studying the effects of school bullying on mental health and suicidal behavior in children and adolescents with different psychosocial profiles. This implies that future studies should have more thorough inclusion criteria on the psychosocial, contextual and sociodemographic characteristics of the sample, in order to characterize different social profiles and generate comparisons between them in terms of school bullying, depression and suicidal behavior.

The second line is to take the set of these psychosocial, contextual and sociodemographic characteristics as independent variables and study the effect they have on school bullying, mental health and suicidal behavior in children and adolescents. This would help to determine the set of psychosocial and contextual factors that could operate as mediating, moderating or controlling variables in the associations between the proposed variables. Indeed, this line of study would not necessarily be about the effects of school bullying, but about the set of psychosocial risk and vulnerability variables that could be associated with suicidal behavior and other psychological indicators.

A third limitation is the relatively small sample size, which meant that it was a population at psychosocial risk, selected taking into account the socioeconomic and psychosocial risk context to which they belonged.

However, the findings are consistent with the empirical evidence reported in studies with much larger samples, which adds strength to the findings. In this sense, the results are applicable to adolescents with the characteristics described in this study and cannot be generalized to a community in general. For future studies, it is recommended that larger samples be used and that the inclusion criteria be more 
precisely defined with respect to the characteristics and psychosocial profiles of the population.

Fourth, the measures of school bullying, depression, suicide risk and attempted suicide were based on self-reporting, and are therefore not free of social desirability bias, precisely because both attempted suicide and school violence are socially undesirable behaviors. For future studies, it is advisable to use key informants, for example, parents, educators or psychosocial teams, in order to contrast the reports of adolescent children with the heteroinformants.

\section{References}

Abello, D., Cortés, O., Barros, O., Mercado, S., \& Solano, D. (2014). Prevalencia de depresión infantil en colegios oficiales de Barranquilla [Infantile depression prevalence in Barranquilla official schools]. Tesis Psicologica, 9, 190-201.

Aguirre, D., Cataño, J., Cañon, S., Marín, D., Rodríguez, J., Rosera, L., Valenzuela, A., \& Vélez, J. (2013). Riesgo suicida y factores asociados en adolescentes de tres colegios de la ciudad de Manizales (Colombia), 2013 [Suicide risk and associated factors in adolescents of three schools of Manizales city (Colombia), 2013]. Revista Facultad de Medicina, 63, 419-29. doi: 10.15446/revfacmed.v63n3.44205

Amezquita, M., González, R., \& Zuluaga, D. (2008). Prevalencia de depresión e ideación suicida en estudiantes de $8^{\circ}, 9^{\circ}, 10^{\circ}$ y $11^{\circ}$ grado, en ocho colegios oficiales de Manizales [Prevalence of depression and suicidal thoughts in students from 8th to 11 th grade in eight public High Schools in Manizales]. Revista Hacia la Promoción de la Salud, 13, 143153.

Andrade, J., \& Gonzáles, J. (2017). Relación entre riesgo suicida, autoestima, desesperanza y estilos de socialización parental en estudiantes de bachillerato [Relations between suicidal risk, self-steem, despair and parental socialization styles in high school students]. Psicogente, 20, 70-88. doi: 10.17081/psico.20.37.2419

Arenas, A., Gómez C., \& Rondón, M. (2016). Factores asociados a la conducta suicida en Colombia. Resultados de la Encuesta Nacional de Salud Mental 2015 [Suicidal behaviour and associated factors in Colombia. Results from the 2015 National Mental Health Survey]. Revista Colombiana de Psiquiatría, 45, 68-75. doi: 10.1016/j.rcp.2016.03.006

Álvarez, J. M., Cañón, S. C., Castaño, J. J., Bernier, L. H., Cataño, A. M., Galdino, P. V., Gil, L. F., Malaver, J. S., Robayo, M. R., \& Sánchez, C. M. (2013). Factor de riesgo suicida y factores asociados en adolescentes de una institución educativa de Palestina - Caldas (Colombia) [Suicidal risk factor and associated factors in adolescents of an educational institution of Palestina, Caldas (Colombia), 2012]. Archivos de Medicina, 13, 127-141.

Barzilay, S., Brunstein, A., Apter, A., Carli, V., Wasserman, C., Hadlaczky, G., Hoven, C., Sarchiapone, M., Balazs, J., Kereszteny, A. Brunner, R., Kaess, M., Bobes, J., Saiz, P., Cosman, D., Haring, C., Banzer, R., Corcoran, P., Kahn, J. P., Postuvan, V., Podlogar, T., Sisask, M., Varnik, A., \& Wasserman, D. (2017). Bullying victimization and suicide ideation and behavior among adolescents in Europe: a 10-country study. Journal of Adolescent Health, 61, 179-186. doi: 10.1016/j.jadohealth.2017.02.002

Bauman, S., Toomey, R. B., \& Walker, J. L. (2013). Associations among bullying, cyberbullying, and suicide in high school students. Journal of Adolescence, 36, 341-350. doi: 10.1016/j.adolescence.2012.12.001

Bella, M., Acosta, L., Villace, B., Lopez, M., Enders, J., \& Fernandez, R. (2013). Análisis de la mortalidad por suicidio en niños, adolescentes y jóvenes [Analysis of mortality from suicide in children, adolescents and youth]. Archivos Argentinos de pediatria, 111, 1621. 
Borowsky, I. W., Ireland, M., \& Resnick, M. D. (2001). Adolescent suicide attempts: Risks and protectors. Official Journal of the American Academy of Pediatrics, 107, 485-493. doi: 10.1542/peds.107.3.485

Borges, G., Benjet, C., Medina-Mora, M. E., Orozco, R., \& Nock, M. (2018). Suicide ideation, plan, and attempt in the Mexican adolescent mental health survey. Journal of the American Academy of Child and Adolescent Psychiatry, 47, 41-52. doi: 10.1097/chi.0b013e31815896ad

Brunstein, A., Barzilay, S., Apter, A., Carli, V., Hoven, C. W., Sarchiapone, M., Hadlaczky, G., Balazs J., Kereszteny, A., Brunner, R., Kaess, M., Bobes, J., Saiz, P., Cosman, D., Haring, C., Banzer, R., McMahon, E., Keeley, H., Kahn, J. P., Postuvan, V., Podlogar, T., Sisask, M., Varnik, A., \& Wasserman, D. (2018). Bi-directional longitudinal associations between different types of bullying victimization, suicide ideation/attempts, and depression among a large sample of European adolescents. Journal of Child Psychology and Psychiatry, 60, 209-215. doi: 10.1111/jcpp.12951

Byrne, B. (2016). Structural equation modeling with Amos (3a ed.). New York, NY: Routledge. Cash, S. J., \& Bridge, J. A. (2009). Epidemiology of youth suicide and suicidal behavior. Current Opinion in Pediatrics, 21, 613-619. doi: 10.1097/mop.0b013e32833063e1

Cabrejos, C., Kruger, H., \& Salmavides, F. (2005). Intento de suicidio en niños y adolescentes, sus características biopsicosociales y diagnósticos psiquiátricos [Suicide intent in children and adolescents, their biopsychosocial characteristics and psychiatric diagnoses]. Revista Neuro-Psiquiatrica, 68, 55-66.

Castaño, J., Constanza, S., Betancur, M., Castellanos, P., Guerrero, J., Gallego, A., \& Llanos, C. (2015). Factor de riesgo suicida según dos cuestionarios y factores asociados en estudiantes de la universidad nacional de Colombia sede Manizales [Suicide risk factors measured with two questionnaires, and associated factors among students of the Universidad Nacional de Colombia of Manizales]. Revistas Diversitas - Perspectivas en Psicología, 11, 193-205.

Cassiani, C., Gómez, J., Cubides, A., \& Hernández, M. (2014). Prevalencia de bullying y factores relacionados en estudiantes de bachillerato de una institución educativa de Cali, Colombia, 2011 [Bullying and its related factors amongst High School students From a school in Cali, Colombia]. Revista de Salud Pública, 16, 14-26. doi: 10.15446/rsap.v16n1.43490

Cañón, S. C., Castaño, J. J., Atehortúa, B. E., Botero, P., García, L. K., Rodríguez, L. M., Tovar, C. A., \& Rincón, E. (2012). Factor de riesgo para suicidio según dos cuestionarios y factores asociados en población estudiantil de la Universidad de Manizales (Colombia), 2011 [Risk factor for suicide according to two questionnaires and factors linked to the student population of an University in Manizales (Colombia), 2011]. Psicología desde el Caribe, 29, 632-664.

Ceballos, G. A., Suárez, Y., Suescun, J., Gamarra, L. M., González, K. E., \& Sotelo, A. P. (2015). Ideación suicida, depresión y autoestima en adolescentes escolares de Santa Marta [Suicidal ideation, depression and self-esteem in teenagers school in Santa Marta]. Revista Internacional de Ciencias de la Salud, 12, 15- 22. doi: 10.21676/2389783X.1394

Ceballos, G., Suárez, Y., \& Campo, A. (2019). Asociación entre matoneo escolar, síntomas depresivos e ideación suicida [Association between school bullying, depressive symptoms and suicidal ideation]. Revista CES Psicologia, 12, 91-104. doi: 10.21615/cesp.12.3.7

Croarkin, P. E., Nakonezny, P. A., Deng, Z. D., Romanowicz, M., Voort, J. L. V., Camsari, D. D., Schak, K. M., Port, J. D., \& Lewis, C. P. (2018). High-frequency repetitive TMS for suicidal ideation in adolescents with depression. Journal of Affective Disorders, 239, 282-290. doi: 10.1016/j.jad.2018.06.048 
Cuevas, M., Hoyos, P., \& Ortiz, Y. (2009). Prevalencia de intimidación en dos instituciones educativas del departamento del Valle del Cauca, 2009 [Prevalence of bullying in two educational institutions in the department of Valle del Cauca, 2009.]. Pensamiento Psicológico, 6, 153-172.

Delgado, L. P., Jaramillo, D. P., Nieto, E., Saldarriaga, G. I., Giraldo, C. L., Sánchez, J. V., Rovira, R., \& Orozco, M. I. (2017). Política Pública de Salud Mental del departamento de Caldas: Un aporte al bienestar y a la inclusión [Mental Health Public Policy of the Department of Caldas: A contribution to wellbeing and inclusión]. Manizales: Editorial Universidad Autónoma de Manizales.

Espelage, D. L., \& Holt, M. K. (2013). Suicidal ideation and school bullying experiences after controlling for depression and delinquency. Journal of Adolescent Health, 53, S27-S31. doi: 10.1016/j.jadohealth.2012.09.017

Fadanellia, M., Lemos, R., Soto, M. F., \& Hiebra, M. (2013). Bullying hasta la muerte. Impacto en el suicidio adolescente [Bullying to death. Impact on adolescent suicide]. Revista Hospital de Niños Buenos Aires, 55, 127-135.

Franklin, J. C., Ribeiro, J. D., Fox, K. R., Bentley, K. H., Kleiman, E. M., Huang, X., Musacchio, K. M., Jaroszewski, A. C., Chang, B. P., \& Nock, M. K (2017). Risk factors for suicidal thoughts and behaviors: A meta-analysis of 50 years of research. Psychological Bulletin, 143, 187-232. doi: 10.1037/bul0000084

Fergusson, D. M., Woodward, L. J., \& Horwood, L. J. (2000). Risk factors and life processes associated with the onset of suicidal behaviour during adolescence and early adulthood. Psychological Medicine, 30, 23-39. doi: 10.1017/s003329179900135x

Fekkes, M., Pijpers, F. I., \& Verloove-Vanhorick, S. P. (2004). Bullying behavior and associations with psychosomatic complaints and depression in victims. Journal of Pediatrics, $144,17-$ 22. doi: 10.1016/j.jpeds.2003.09.025

Fritz, C. O., Morris, P. E., \& Richler, J. J. (2012). Effect size estimates: current use, calculations, and interpretation. Journal of Experimental Psychology: General, 141, 2- 18.

Fuentes, M. M., Gonzales, A. F., Castaño, J. J., Hurtado, C. F., Ocampo, P. A., Páez, M. L., Pava. D. M., \& Zuluaga, L. M. (2009). Riesgo suicida y factores de riesgo relacionados, en estudiantes de $6^{\circ}$ a $11^{\circ}$ grado en colegios de Manizales (Colombia) 2007-2008 [Suicide risk and related factors at students of $6^{\circ}$ to $11^{\circ}$ grades in different schools of Manizales City (Colombia). 2007-2008]. Archivos de Medicina, 9, 110-122. doi: 10.30554/archmed.9.2.1311.2009

Geoffroy, M. C., Boivin, M., Arseneault, L., Turecki, G., Vitaro, F., Brendgen, M., Renaud, J., Séguin, J., Tremblay, R., \& Côté, S. M. (2016). Associations between peer victimization and suicidal ideation and suicide attempt during adolescence: results from a prospective population-based birth cohort. Journal of the American Academy of Child \& Adolescent Psychiatry, 55, 99-105. doi: 10.1016/j.jaac.2015.11.010

Gómez, A. S., Núñez, C., Caballo, V. E., Agudelo, M. P., \& Grisales, A. M. (2019). Predictores psicológicos del riesgo suicida en estudiantes universitarios [Psychological predictors of suicidal risk in college students]. Behavioral Psychology/Psicología Conductual, 27(3)، 391-413.

Gómez, A. S., Núñez, C., Agudelo, M. P., \& Grisales, A. M. (2020). Riesgo e Ideación Suicida y su Relación con la Impulsividad y la Depresión en Adolescentes Escolares [Risk and Suicidal Ideation and its Relationship with Impulsivity and Depression in School Adolescent]. Revista Iberoamericana de Diagnóstico y Evaluación - e Avaliação Psicológica. RIDEP, 54, 147-163. doi: 10.21865/RIDEP54.1.12

Gould, M. S., King, R., Greenwald, S., Fisher, P., Schwab-Stone, M., Kramer, R., \& Shaffer, D. (1998). Psychopathology associated with suicidal ideation and attempts among children and adolescents. Journal of the American Academy of Child \& Adolescent Psychiatry, 37, 915-923. doi: 10.1097/00004583-199809000-00011 
Herrera, E., Losada, Y., Rojas, I., \& Gooding, P. (2009). Prevalencia de la depresión infantil en Neiva (Colombia) [Prevalence of child depression in Neiva (Colombia)]. Revista Avances en Psicología Latinoamericana, 27, 154-164

Hayes, A. F. (2018). Introduction to mediation, moderation, and conditional process analysis (2nd ed.). New York, NY: Guilford.

Hinduja, S., \& Patchin, J. W. (2010). Bullying, cyberbullying, and suicide. Archives of Suicide Research, 14, 206-221. doi: 10.1080/13811118.2010.494133

Hinduja, S., \& Patchin, J. W. (2018). Connecting adolescent suicide to the severity of bullying and cyberbullying. Journal of School Violence, 18, 333-346. doi: 10.1080/15388220.2018.1492417

Instituto Nacional de Medicina Legal y Ciencias Forenses- INMLCF. (2019). Informe Forensis datos para la vida. Bogotá: Grupo Centro de Referencia Nacional Sobre Violencia. Retrieved from: https://www.medicinalegal.gov.co/documents/20143/386932/Forensis +2018.pdf/be4816 a4-3da3-1ff0-2779-e7b5e3962d60

Kessler, R. C., Borges, G., \& Walters, E. E. (1999). Prevalence of and risk factors for lifetime suicide attempts in the National Comorbidity Survey. Archives of General Psychiatry, 56, 617-626. doi:10.1001/archpsyc.56.7.617

Kim, Y. S., Koh, Y., \& Leventhal, B. (2005). School bullying and suicidal risk in Korean middle school students. Official Journal of the American Academy of Pediatrics, 115, 357-363. doi: 10.1542/peds.2004-0902

Kim, Y. K., Yang, M.Y., Barthelemy, J. J., \& Lofaso, B. M. (2018). A binary gender analysis to bullying, dating violence, and attempted suicide: The disproportionate effect of depression and psychological harm. Children and Youth Services Review, 90, 141-148. doi: 10.1016/j.childyouth.2018.05.028

Klomek, A. B., Kleinman, M., Altschuler, E., Marrocco, F., Amakawa, L., \& Gould, M. S. (2011). High school bullying as a risk for later depression and suicidality. Suicide and Life-Threatening Behavior, 41, 501-516. doi: 10.1111/j.1943-278x.2011.00046.x

Kovacs, M. (1992). Children's Depression Inventory. New York, NY: Pearson.

Kowalski, R., \& Limber, S. (2013). Psychological, physical, and academic correlates of cyberbullying and traditional bullying. Journal of Adolescent Health, 53, 513-520. doi: 10.1016/j.jadohealth.2012.09.018

Kodish, T., Herres, J., Shearer, A., Atte, T., Fein, J., \& Diamond, G. (2016). Bullying, depression, and suicide risk in a pediatric primary care sample. Crisis, 37, 241-246. doi: 10.1027/0227-5910/a000378

Koyanagi, A., Oh, H., Carvalho, A. F., Smith, L., Haro, J. M., Vancampfort, D., Stubbs, B., \& DeVylder, J. E. (2019). Bullying victimization and suicide attempt among adolescents aged 12-15 years from 48 countries. Journal of the American Academy of Child \& Adolescent Psychiatry., 58,907-918. doi: 10.1016/j.jaac.2018.10.018

Liu, Z. Z., Chen, H., Bo, Q. G., Chen, R. H., Li, F. W., Lv, L., Jia, C. X., \& Liu, X. (2018). Psychological and behavioral characteristics of suicide attempts and non-suicidal selfinjury in Chinese adolescents. Journal of Affective Disorders, 226, 287-293. doi: 10.1016/j.jad.2017.10.010

McArdle, J. J., \& Nesselroade, J. R. (2014). Basics of structural equation modeling. In J. J. McArdle, \& J. R. Nesselroade (Eds.), Longitudinal data analysis using structural equation models (pp. 27-37). Washington, DC: American Psychological Association.

Modecki, K. L., Minchin, J., Harbaugh, A. G., Guerra, N. G., \& Runions, K. C. (2014). Bullying prevalence across contexts: A meta-analysis measuring cyber and traditional bullying. Journal of Adolescent Health, 55, 602-611. doi: 10.1016/j.jadohealth.2014.06.007

Mosquera, L. (2016). Conducta suicida en la infancia: una revisión crítica [Suicidal behavior in childhood: A critical review]. Revista de Psicología Clínica con Niños y Adolescentes, 3, 9-18. 
Moratto, N., Cárdenas, N., \& Berbesí, D. (2012). Validación de un cuestionario breve para detectar intimidación escolar [Validation of a Short Questionnaire to detect School Bullying]. Revista CES Psicología, 5, 70-78

Mortier, P., Auerbach, R. P., Alonso, J., Bantjes, J., Benjet, C., Cuijpers, P., Ebert, D., Green, J. G., Hasking, P., Nock, M. K., O'Neill, S., Pinder-Amaker, S., Sampson, N. A., Vilagut, G., Zaslavsky, A. M., Bruffaerts, R., Kessler, R. C., \& WHO WMH-ICS Collaborators. (2018). Suicidal thoughts and behaviors among first-year college students: Results from the WMH-ICS project. Journal of the American Academy of Child \& Adolescent Psychiatry, 57, 263-273. doi: 10.1002\%2Fmpr.1752

Nock, M. K., Green, J. G., Hwang, I., McLaughlin, K. A., Sampson, N. A., Zaslavsky, A. M., \& Kessler, R. C. (2013). Prevalence, correlates, and treatment of lifetime suicidal behavior among adolescents. JAMA Psychiatry, 70, 300-310. doi: 10.1001/2013.jamapsychiatry. 55

Organización Mundial de la Salud. (2018a). Suicide. Retrieved from: https://www.who.int/es /news-room/fact-sheets/detail/suicide

Organización Mundial de la Salud. (2018b). World Health Statistics 2018. Monitoring health for the SDGs. Retrieved from: https://apps.who.int/iris/bitstream/handle/10665/272596 /9789241565585-eng.pdf?ua=1

Organización de las Naciones Unidas. (2017). La población mundial aumentara en 1.000 millones para 2030. Retrieved from: https://www.un.org/development/desa/es/news/ population/world-population-prospects2017.html

Organización Panamericana de la Salud. (2014). Mortalidad por suicidio en las Américas. Retrieved from: https://www.paho.org/hq/dmdocuments/2014/PAHO-Mortalidadporsuicidio-final.pdf.

Orri, M., Galera, C., Turecki, G., Forte, A., Renaud, J., Boivin, M., \& Geoffroy, M. C. (2018). Association of childhood irritability and depressive/anxious mood profiles with adolescent suicidal ideation and attempts. JAMA Psychiatry, 75, 465-473. doi: 10.1001/jamapsychiatry.2018.0174

Paredes, M., Álvarez, M., Lega, L., \& Vernon, A. (2008). Estudio exploratorio sobre el fenómeno del "Bullying" en la ciudad de Cali, Colombia [An exploratory study on the phenomenon of "bullying" in the city of Cali, Colombia]. Revista Latinoamericana de Ciencias Sociales, Niñez y Juventud, 6, 295-317.

Park, S., \& Jang, H. (2018). Correlations between suicide rates and the prevalence of suicide risk factors among Korean adolescents. Psychiatry Research, 261, 143-147. doi: 10.1016/j.psychres.2017.12.055

Plutchick, R., \& Van Praag, H. (1989). The measurement of suicidality, aggressivity and impulsivity. Progress in Neuro-Psychopharmacology \& Biological Psychiatry, 6, 23-34. doi: 10.1016/0278-5846(89)90107-3

Reed, K. P., Nugent, W., \& Cooper, R. L. (2015). Testing a path model of relationships between gender, age, and bullying victimization and violent behavior, substance abuse, depression, suicidal ideation, and suicide attempts in adolescents. Children and Youth Services Review, 55, 128-137. doi: 10.1016/j.childyouth.2015.05.016

Rubio, G., Montero, I., Jáuregui, J., Villanueva, R., Casado, M. A., Marín, J. J., \& SantoDomingo, J. (1998). Validación de la Escala de riesgo suicida de Plutchik en población española [Validation of the Plutchik Suicide Risk Scale in a Spanish population]. Archivos de Neurobiología 61, 143-52.

Sandoval, R., Vilela, M., Mejía, C., \& Caballero, J. (2018). Suicide risk associated with bullying and depression in High School. Revista Chilena de Pediatría, 89, 208-215. doi: $10.4067 /$ S0370-41062018000200208

Sánchez, P. V. (2013). El bullying como construcción social, más allá de las víctimas, los agresores y los testigos... la familia, los docentes y la sociedad [Bullying as social 
construction, beyond the victims, the offendersand the witnesses, ... the family, teachers, and society]. Revista Latinoamericana de Estudios de Familia 5, 222-247.

Sánchez, P. V. (2017). La participación, la responsabilidad social y la vida en comunidad como ejes para abordar la intimidación escolar [Participation, social responsibility and communitylife as elements to face school bullying]. Pensamiento Psicológico, 15, 121 132. doi: 10.11144/Javerianacali.PPSI15-2.prsv

Santana, M. A., \& Santoyo, F. (2018). Propiedades psicométricas de la escala riesgo suicida de Plutchik en una muestra de jóvenes mexicanos privados de la libertad [Psychometric properties of the Plutchik Suicide Risk Scale in a sample of young Mexicans deprived of liberty]. Avances en Psicología, 26, 57-64. doi: 10.33539/avpsicol.2018.v26n2.1127

Sampasa-Kanyinga, H., Roumeliotis, P., \& Xu, H. (2014 Associations between cyberbullying and school bullying victimization and suicidal ideation plans and attempts among Canadian schoolchildren. PLOS ONE, 9, e102145. doi: 10.1371/journal.pone.0102145

Schneider, S. K., O'Donnell, L., Stueve, A., \& Coulter, R. S. (2012). Cyberbullying, school bullying, and psychological sistress: A regional census of high school students. American Journal of Public Health, 102, 171-177. doi: 10.2105/AJPH.2011.300308

Siabato, E., Forero, I. X., \& Salamanca, Y. (2017). Asociación entre depresión e ideación suicida en un grupo de adolescentes colombianos [Association between depression and suicidal ideation in a group of Colombian adolescents]. Pensamiento Psicológico, 15, $51-61$.

Tan, L., Xia, T., \& Reece, C. (2016). Social and individual risk factors for suicide ideation among Chinese children and adolescents: A multilevel analysis. International Journal of Psychology, 53,117-125. doi: 10.1002/ijop.12273

Uribe, A., Orcasita, L., \& Aguillón, E. (2012). Bullying, redes de apoyo social y funcionamiento familiar en adolescentes de una institución educativa de Santander, Colombia [Bullying, social support networks and family functioning in adolescents in an educational institution Santander, Colombia]. Psychologia, 6, 83-99. doi: 10.21500/19002386.1186

Valadez, I., Amezcua, R., González, N., Montes, R., \& Vargas, V. (2011). Maltrato entre iguales e intento suicida en sujetos adolescentes escolarizados [Peer mistreatment and suicide attempt in adolescents that go to school]. Revista Latinoamericana de Ciencias Sociales, Niñez y Juventud, 2, 783 - 796.

Van Geel, M., Vedder, P., \& Tanilon, J. (2014). Relationship between peer victimization, cyberbullying, and suicide in children and adolescents. JAMA Pediatrics, 168, 435442. doi: 10.1001/jamapediatrics.2013.4143

Vega, L. A., Fernández, A. A., \& Giraldo, N. R. (2017). Los entornos sociales y su relación con el conflicto y la violencia escolar en las ciudades de Armenia y Manizales, Colombia [Social environments and their relation to conflict and school violence in the cities of Armenia and Manizales, Colombia]. Sophia, 13, 34-46. doi: 10.18634/sophiaj.13v.1i.684

Villalobos, F. H. (2009) Situación de la conducta suicida en estudiantes de colegios y universidades de San Juan de Pasto, Colombia [Suicidal behaivor in High School and college students in San Juan de Pasto, Colombia]. Salud Mental, 32, 165-171.

Wahlbeck, K. (2015). Public mental health: The time is ripe for translation of evidence into practice. World Psychiatry, 14, 36-42. doi: 10.1002/wps.20178

Zakharov, S., Navratil, T., \& Pelclova, D. (2013). Suicide attempts by deliberate self-poisoning in children and adolescents. Psychiatry Research, 210, 302-307. doi: 10.1016/j.psychres.2013.03.0

RECEIVED: June 30, 2020

ACCEPTED: November 14, 2020 